\title{
TONELLI JUSTINIANO Oscar, El caucho ignorado
}

\section{Lorena I. Córdoba}

\section{OpenEdition}

\section{Journals}

\section{Edición electrónica}

URL: https://journals.openedition.org/jsa/11999

DOI: 10.4000/jsa.11999

ISSN: 1957-7842

Editor

Société des américanistes

\section{Edición impresa}

Fecha de publicación: 20 diciembre 2011

Paginación: 419-422

ISSN: 0037-9174

\section{Referencia electrónica}

Lorena I. Córdoba, "TonelLI Justiniano Oscar, El caucho ignorado», Journal de la Société des américanistes [En línea], 97-2 | 2011, Publicado el 22 diciembre 2011, consultado el 03 septiembre 2022. URL: http:// journals.openedition.org/jsa/11999 ; DOI: https://doi.org/10.4000/jsa.11999

Este documento fue generado automáticamente el 3 septiembre 2022.

All rights reserved 


\title{
TONELLI JUSTINIANO Oscar, El caucho ignorado
}

\author{
Lorena I. Córdoba
}

\section{REFERENCIA}

TONELLi JUSTINIANO Oscar, El caucho ignorado, Editorial El País, col. « Ciencias Sociales/

Historia » 19, Santa Cruz de la Sierra, 2010, 327 p.

1 Cuando se habla del « oro que manaba de los árboles » o de « la fiebre del oro blanco » es obvio que nos referimos a un periodo muy particular de la historia boliviana. El auge del caucho o de la goma, como se lo suele denominar, ha sido protagonista de varios libros y artículos escritos por investigadores tanto nacionales como internacionales (podemos citar a modo de ejemplo los trabajos de Ballivián 1896; Ballivián y Casco 1912; Pando 1897; Chávez 2009; Roca 2001; Gamarra Téllez 2007; Fifer 1966, 1970; García Jordán 2001, etc.). Distinto hubiera sido el destino del norte boliviano de no haberse explotado el caucho, y otra habría sido definitivamente la historia de las tierras bajas de no haber sido moldeada por una actividad lucrativa que provocó, entre otras cosas, conflictos fronterizos con el Brasil, la guerra del Acre y la consecuente pérdida de una vasta porción del territorio nacional. En este libro de Oscar Tonelli Justiniano volvemos a encontrarnos con la problemática del caucho; pero, como bien indica el título, se trata de un caucho « olvidado » puesto que los investigadores se han interesado poco por la producción del mismo fuera del Beni y sus alrededores. En efecto, el autor centra su trabajo en el desarrollo económico y las relaciones sociales, políticas y obviamente comerciales que provocó la actividad cauchera en otra región de Bolivia, la Chiquitanía y, en particular, los bosques del norte de las provincias cruceñas de Velasco y Ñuflo de Chávez. El libro, además, tiene la novedad de analizar el último coletazo de la explotación cauchera desde la década de 1950 hasta entrada la década de 1980 -, cuando hubo un revival de la industria y una renovación exportadora por varios años hasta su nuevo ocaso. 
2 Tonelli Justiniano comienza con una breve introducción al medioambiente regional (ríos, clima, vegetación), así como también a la historia del descubrimiento del caucho tanto a nivel mundial como a nivel amazónico, para luego desarrollar el caso particular de la Chiquitanía. Combinando fuentes históricas con el relato que los propios exploradores publicaban en los periódicos locales, determina con exactitud la fecha del hallazgo del caucho en el septentrión chiquitano: entre noviembre y diciembre de 1892, en efecto, una comitiva compuesta por los vecinos Miguel Añez, Arístides Romero, Emilio Peña y José M. Durán comunica el hallazgo de enormes cantidades de « siringa » (término regional para denominar el caucho).

3 Uno de los capítulos más interesantes del libro es dedicado a la descripción técnica de esta actividad extractiva. Tonelli Justiniano analiza por ejemplo los términos que muchas veces derivan o son deformaciones de vocablos portugueses utilizados en Brasil; de igual modo, explica a quién se denomina "picador», qué es un "rayador» o un «machadiño", cuánto mide una estrada, cuánto dura una extracción, etc. También describe en detalle los procedimientos del proceso productivo: por ejemplo, los pormenores de la transformación del látex en sernamby (producido, entre otras modalidades, cuando el agua de lluvia cae en la tichela diluyendo la savia y acelerando el proceso de coagulación). También da cuenta exhaustivamente de cuestiones como las barracas gomeras, los centros y las periferias de las casas centrales, la calidad comparativa del empleo, las relaciones entre los patrones, los fregueses y los capataces.

4 La parte más significativa de la argumentación, de hecho, concierne la estructura social del auge cauchero. Desde sus comienzos la actividad comprometió a la mayoría de los pobladores de la Chiquitanía, dado que, de una u otra forma, casi todos participaron en la explotación cauchera ya fuese en el transporte de la carga, en el comercio, en el financiamiento, en el aprovisionamiento de mercadería, en la venta o reventa de la materia prima. Tal como sucedió en el norte amazónico boliviano, la región no podía quedar impávida frente al fantástico crecimiento económico suscitado por la fiebre del caucho. Surgen nuevas asociaciones entre vecinos para explotar los gomales, así como también se rompen viejas alianzas comerciales. Los emprendimientos del periodo son frágiles y mutan en la misma medida en que cambian los diversos actores sociales: así, pronto surgen nuevos nombres que llegan desde otras regiones alterando la geografía social y política mientras que modifican o amplían las relaciones socioeconómicas regionales con el resto del país y, principalmente, con el emporio cauchero del Beni. Para graficar el despliegue de estas nuevas redes sociales, Tonelli Justiniano presenta una breve genealogía de cada uno de los actores cruceños que marcharon al norte de Velasco y trabajaron el caucho en los ríos Verde, Paraguá y Tarbo - así, por ejemplo, resulta significativa la posibilidad de rastrear lazos comerciales y de parentesco con otras dinastías caucheras de Bolivia como en el caso de Liberato Justiniano Moreno, casado con María Domitila Suárez, prima hermana del célebre cauchero norteño Nicolás Suárez.

5 Este proceso de intenso cambio social se reflejó inevitablemente en altercados, luchas y asesinatos motivados por la codicia cauchera. El autor describe varias disputas de fregueses y aun de un subprefecto a través de cartas personales de los personajes de la época, así como también de los periódicos regionales. El más famoso de estos episodios fue el llamado « asesinato de la calle Ballivián » en el cual murió Manuel Peña Álvarez, siendo sindicado como autor intelectual del crimen de otro importante barón cauchero: el doctor Pontieno Rojas Vázquez. En efecto, como siempre en la historia cauchera, la industria reveló su costado oscuro, desalmado y cruel. El auge económico de finales del 
siglo xIX y principios del siglo xx trajo aparejada una voracidad de mano de obra que muchas veces no podía ser satisfecha por la población regional; en consecuencia, los caucheros idearon varios métodos para mantener un número constante de peones en las barracas, movilizando gente de todas partes del país a veces por propia voluntad, y otras tantas forzadas por procedimientos como la leva o el enganche. Tonelli Justiniano describe la relación entre el sistema de reenganche y la ley promulgada por el gobierno boliviano en 1896, por medio de la cual los gomales se poblaron de los «indígenas chiquitanos, mezclándose en las selvas de la región, el altivo e inteligente ignaciano, el valiente y sagaz aneño, el ladino y leguleyo migueleño, el dócil y bonachón javiereño, el pícaro y temeroso concepcioneño, el esforzado y obstinado josesano y el astuto y taciturno rafaeleño » (p. 107). Más allá de la adjetivación pintoresca, lo cierto es que el libro confirma lo que en 1909 había advertido el etnólogo sueco Nordenskiöld (2003, p. 124) durante su viaje por Bolivia: «Sin indios no hay industria del caucho ». En este sentido, una pequeña crítica en este punto podría ser que quienes se interesan también por la etnología de la región habrían apreciado una mayor profundización en cuanto a la identificación concreta de los indígenas caucheros: las referencias muchas veces son vagas y no aportan gran detalle para identificar a los grupos étnicos involucrados.

Para concluir, podemos decir que la obra cubre temas diversos que van desde la orografía, la hidrografía o la historia regional hasta el análisis específico del auge gomero y las enfermedades endémicas asociadas con la actividad. También que las historias locales son narradas con gran sencillez, e incluso con algunos guiños cómplices, casi humorísticos, en un estilo cándido que tanto por los temas como por la forma recuerda Eldorado boliviano del historiador boliviano Chávez - por citar un único ejemplo: « El nombre chori fue dado genéricamente a los silvícolas de habla guaraní. Para mí este nombre tiene una connotación especial, pues fue el de la comparsa que con otros siete amigos fundamos en 1957, cuando nos separamos de los “Zánganos" » (p. 117).

\section{BIBLIOGRAFÍA}

\section{BALLIVIÁN Manuel}

1896 Apuntes sobre la industria de la goma elástica en los territorios dependientes de la delegación nacional en el Noroeste y el departamento del Beni, Ministerio de Instrucción Pública y Colonización, La Paz.

BaLlivián Manuel y Pinilla casco

1912 Monografía de la industria de la goma elástica en Bolivia, Dirección General de Estadística y Estudios Geográficos, La Paz.

CHÁvEZ Medardo

2009 Eldorado boliviano, Fundación Nova, Santa Cruz de la Sierra.

FIFER J. Valerie

1966 « Bolivia's boundary with Brazil: a century of evolution », The Geographical Journal, 132 (3), pp. 360-372. 
1970 « The Empire builders: a history of the Bolivian rubber boom and the rise of the house of Suarez », Journal of Latin American Studies, 2 (2), pp. 113-146.

\section{GAMARRA TÉLleZ María del Pilar}

2007 Amazonía Norte de Bolivia. Economía gomera (1870-1940), Colegio Nacional de Historiadores de Bolivia/CIMA, La Paz.

\section{GARCíA Jordán Pilar}

2001 « En el corazón de las tinieblas... del Putumayo, 1890-1932. Fronteras, caucho, mano de obra indígena y misiones católicas en la nacionalización de la Amazonía ", Revista de Indias, 61 (223), pp. 591-617.

NORDENSKIÖLD Erland

2003 Indios y blancos, APCOB/Plural, La Paz.

PANDO José M.

1897 Viaje a la región de la goma elástica (Noroeste de Bolivia), El Comercio, Cochabamba.

ROCA José Luis

2001 Economía y sociedad en el Oriente boliviano (siglos XVI-XX), COTAS, Santa Cruz de la Sierra.

\section{AUTORES}

\section{LORENA I. CÓRDOBA}

CONICET/UBA, Argentine 